\title{
ARAUCARTAS: O JOGO DE CARTAS COMO FERRAMENTA DE EDUCAÇÃO AMBIENTAL PARA ABORDAGEM DA BIODIVERSIDADE
}

Lucas Sautchuk ${ }^{1}$

\author{
Lia Maris Orth Ritter Antiqueira²
}

Resumo: A biodiversidade brasileira precisa ser tratada além dos conhecimentos de Ciências e Biologia, considerando a Educação Ambiental como subsídio para o desenvolvimento da consciência cidadã. Este artigo apresenta a proposta de um jogo de cartas como potencial recurso didático para abordar a riqueza do patrimônio natural da região dos Campos Gerais, Paraná. Acredita-se que este material pode ser uma alternativa no processo de ensino-aprendizagem ao ressaltar a importância da preservação da Floresta com Araucária, da fauna associada e das paisagens cênicas, bem como ressaltar a importância da criação e manutenção de Unidades de Conservação. O material possui baixo custo para confecção e foi disponibilizado gratuitamente por meio de um site a fim de contribuir com professores na difícil tarefa de ensinar conteúdos tão importantes, especialmente no período de pandemia com atividades remotas.

Palavras-chave: Campos Gerais; Educação Ambiental; Mata de Araucária.

Abstract: Brazilian biodiversity needs to be worked on beyond the knowledge of Science and Biology, considering Environmental Education as a subsidy for the development of citizen awareness. This article presents the proposal of a card game as a potential didactic resource to address the richness of the natural heritage of the Campos Gerais region, Paraná. It is believed that this material can be an alternative to help in the teaching-learning process by emphasizing the importance of preserving the Araucaria Forest, associated fauna and scenic landscapes, as well as highlighting the importance of creating and maintaining Conservation Units. The material has low cost for making and was made available for free through a website in order to contribute with teachers in the difficult task of teaching such important contents, especially in the period of pandemic with remote activities.

Keywords: Campos Gerais; Enviromental Education; Araucaria forest. 


\section{Introdução}

Os jogos são ferramentas didáticas importantes na Educação Ambiental, permitindo ao aluno conhecer e aprender um determinado conteúdo enquanto se diverte. A antiga imagem de que os jogos serviam somente para entretenimento vem sendo substituída por uma nova visão, que remete ao teor lúdico e de aprendizagem, desenvolvendo habilidades e promovendo alternativas para chegar em determinados resultados e resolução de problemas.

Dentre os diversos formatos de jogos que podem ser utilizados no ensino básico, o jogo de cartas mostra-se como uma alternativa que pode contribuir no processo de ensino-aprendizagem. Porém, é necessário dedicar tempo ao planejamento e elaboração, considerando os conteúdos que serão abordados e a facilidade de acesso ao material. Também é importante que o tema contemple os conteúdos no contexto em que o aluno vive, de forma que compreenda as questões relacionadas à sua realidade.

Os alunos do ensino básico apresentam dificuldades em aprender conteúdos relacionados à Ciências e Biologia, dada a carga de informações da grade curricular. Este panorama muitas vezes acaba por colaborar com o índice de evasão escolar. No que se refere aos conteúdos relacionados à Botânica, Zoologia e Biodiversidade, é de grande importância que os alunos contextualizem e entendam as características que tornam o Brasil o país com a maior diversidade biológica do mundo.

A região dos Campos Gerais, no estado do Paraná (Bioma Mata Atlântica) possui elevada biodiversidade incluindo espécies raras e endêmicas. Algumas dessas espécies correm risco de extinção devido ao desmatamento de extensas áreas nativas para agricultura e expansão das cidades, causando perda do habitat natural e invasão de espécies exóticas. Estas graves situações requerem discussão e reflexão, a fim de se promover a valorização da natureza e a defesa do patrimônio natural da região.

Sendo assim, se faz necessário abordar o assunto no ensino de Ciências e Biologia, de forma que os alunos compreendam a importância da conservação da natureza, das espécies presentes nos mais variados habitats e dos processos ecológicos envolvidos. Nestas premissas a questão norteadora deste estudo foi a proposta de desenvolvimento de um jogo de cartas para o ensino de conteúdos relacionados à Biodiversidade dos Campos Gerais.

Especificamente propôs-se apresentar um material de fácil replicabilidade, incluindo moldes e instruções que pudessem ser obtidos de forma gratuita pelos interessados e assim contribuir com possibilidades de materiais diferenciados para o ensino de Ciências e Biologia. 


\section{A Biodiversidade dos Campos Gerais}

A região dos Campos Gerais, no estado do Paraná (Figura 1), faz parte do Bioma Mata Atlântica, no qual se insere a formação denominada Floresta Ombrófila Mista, ou Floresta com Araucária. Compreendem os campos limpos e de Cerrado na borda do segundo planalto paranaense, possuindo delimitação pela Escarpa Devoniana abrangendo 22 municípios (MELLO; MORO; GUIMARÃES, 2010).

Buscando preservar os ambientes naturais existentes na região, realizar pesquisas científicas e desenvolver atividades de educação ambiental e turismo ecológico, uma das iniciativas foi a criação do Parque Nacional dos Campos Gerais (PNCG) em 2006 (ANTIQUEIRA; MORO, 2019). O PNCG é administrado pelo Instituto Chico Mendes de Biodiversidade e embora ainda não tenha passado por regularização fundiária é um espaço de grande potencial para estudos.

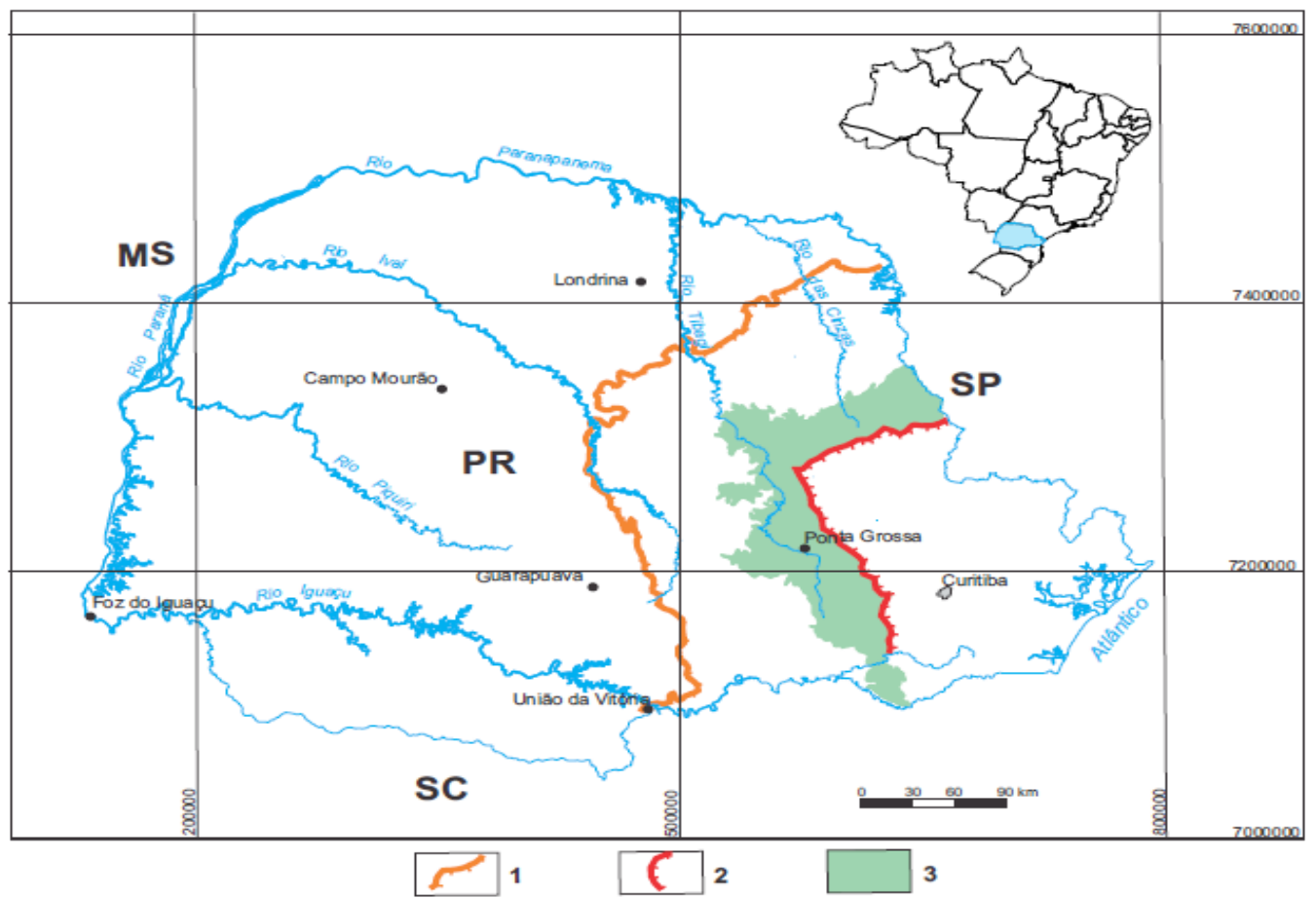

Figura 1: Delimitação da região dos Campos Gerais no estado do Paraná (em verde), incluindo a Serra Geral (1) e a Escarpa Devoniana (2).

Fonte: Mello; Moro e Guimarães (2010)

No PNCG, assim como em toda região dos Campos Gerais, há presença de diferentes fitofisionomias. Há campos secos com vegetação herbácea e subarbustiva, que ocorre frequentemente associada aos capões formados pela mata de araucária (Araucaria angustifolia). Há presença de espécies endêmicas como o cacto bolinha (Parodia caramberiensis), e espécies ameaçadas de extinção. Já foram catalogadas aproximadamente setenta famílias e não há um número exato de espécies, visto que extrapolam a casa de milhares (MELLO; MORO; GUIMARÃES, 2010). 
Também há presença de campos úmidos onde ocorrem espécies típicas como a flor-das-almas (Senecio bonariensis), remanescentes Cerrado com presença de árvores raquíticas que são degradadas pelo fogo anual e possuindo espécies ameaçadas de extinção. Segundo Moro e Antiqueira (2019) a espécie comum que caracteriza a savana nos Campos Gerais é o marmelo do cerrado (Plenckia populnea).

A estas fisionomias associa-se uma fauna de equivalente biodiversidade e importância, incluindo espécies carismáticas como a gralha azul (Cyanocorax caeruleus) que é considerada ave símbolo do estado do Paraná e que também se encontra sob forte ameaça de extinção.

Com isso, observa-se que há uma necessidade de preservação destas áreas de elevada biodiversidade, bem como a busca pela utilização dos recursos naturais de forma sustentável. Com o mesmo grau de importância, a inserção do conhecimento sobre o tema no currículo e nas práticas de Ciências e Biologia, contribui com aspectos de Educação Ambiental e sensibilização para a conservação do patrimônio da região.

\section{Contribuição dos jogos no contexto da Educação Ambiental}

A Educação Ambiental é definida por Uhmann e Vorpagel (2018) como um tema transversal fundamental na sensibilização para a tomada de consciência, visto que a crise ambiental decorre principalmente dos meios e dos modos de produção do sistema capitalista. As autoras enfatizam que por meio do processo educativo é possível criar condições de entendimento sobre as questões socioambientais.

Cavalheiro e Nishijima (2014) endossam este posicionamento ao afirmar que a Educação Ambiental na escola contribui na formação dos estudantes quando enfoca aspectos éticos da relação homem-natureza, possibilitando aos alunos pensar criticamente sobre as problemáticas ambientais.

Assim, as estratégias e ferramentas adotadas na educação básica são fundamentais para a construção de conhecimentos de forma crítica, haja vista que as aulas tradicionais expositivas podem por vezes se tornar repetitivas e monótonas. Diversos pesquisadores do campo educacional se debruçam sob este tema buscando alternativas diferenciadas para subsidiar os processos de ensino-aprendizagem. E nesta esfera, autores como Cambréa (2012) sugerem como metodologia de ensino promissora, o uso de jogos didáticos.

Os jogos são materiais didáticos comumente desenvolvidos com 0 objetivo de auxiliar o aprendizado do aluno (CANDIDO et al., 2012), promovendo uma melhora na qualidade de ensino fazendo as aulas mais agradáveis (FOCETOLA et al., 2012,) sendo uma importante ferramenta que o professor pode utilizar em sala de aula (FERNANDES et al., 2014).

Contudo, é importante que o jogo seja pensado para objetivos além da diversão e com adequações para uso em sala de aula. Para tanto, precisa ser 
planejado, estruturado e utilizado de forma que permita a inserção de novos conhecimentos e fixação de outros já aprendidos. Desta forma, além de auxiliar no processo de aprendizagem estimulando a obtenção de conhecimento, os jogos didáticos podem contribuir para o enriquecimento intelectual (ALVES et al., 2010). Mas cabe ao professor planejar a utilização destes jogos e adaptar suas aulas para atender as necessidades dos alunos com relação ao conteúdo a ser abordado.

Para Kishimoto (1994), é necessário considerar que o entendimento de jogos e brincadeiras varia de um indivíduo para outro. Isso ocorre devido a interpretação individual e pela realidade e meio social em que vivem. Há muitos debates da percepção do que é jogo e a sua seriedade sendo que para uns o jogo é visto como entretenimento que deve ser utilizado somente para o lazer, enquanto para outros o jogo é visto como um estado da arte, como no jogo quebra cabeças, onde o aluno pode aprender sobre arte e cultura. Há sempre novos paradigmas que mostram a importância do jogo na fase escolar.

Para os adolescentes, o jogo desenvolve o raciocínio lógico (VYGOTSKY, 1991), sendo que o aluno pode jogar ao mesmo tempo que aprende, conseguindo inclusive relembrar assuntos aprendidos anteriormente (BRAGA et al, 2019).

Porém, existe a necessidade de o estudante ter um conhecimento prévio do assunto, e que durante a aplicação do jogo como a prática tenha uma explicação para assimilar o conhecimento, para que aprenda de forma mais prazerosa, promovendo uma interação com colegas e com o professor (FARIAS et al., 2015).

A produção destes materiais ocorre geralmente nas escolas nas aulas de Artes, porém os professores de outras matérias, utilizando desse recurso conseguiriam interagir com conhecimentos de outras áreas. É preciso desmitificar o uso de jogos somente em aulas de Educação Física o que acaba por tirar o encanto de aprender utilizando esse método, como afirmam Tessaro e Jordão (2007).

\section{Proposta do jogo}

Araucartas foi elaborado com base em pesquisa de literatura e disponibilizado para o público em geral por meio de um site de acesso livre. Porém, o público principal são professores e alunos do ensino fundamental e médio. No site estão disponibilizadas todas as informações necessárias para elaboração das cartas, as regras e os modelos, incluindo medidas e sugestões de materiais de fácil acesso que podem ser reutilizados na confecção das cartas.

Esta estratégia foi adotada como subsídio às atividades remotas desenvolvidas durante a pandemia, com o intuito de que os alunos possam confeccionar e jogar com seus familiares, enquanto aprendem o conteúdo. Outra opção, por exemplo, é de que o professor estimule a confecção do 
material como parte das atividades de suas disciplinas, propondo atividades relacionadas como, por exemplo a composição de textos sobre os conteúdos.

O jogo possui apelo visual, fazendo uso de imagens da fauna, flora e ambientes de elevada beleza cênica encontrados na região dos Campos Gerais. Um trabalho de Silveira e Alves (2008) investigando o potencial da fotografia como recurso metodológico e educativo em Educação Ambiental, explicita as possibilidades de uso na formação de sujeitos ecológicos. Estas considerações foram motivadoras na escolha do jogo de cartas com imagens ao concordar com os autores que a arte constitui metodologia singular pelo seu caráter interdisciplinar, permitindo o desenvolvimento de mecanismos metodológicos e materiais de aprendizagem.

Para a confecção do modelo base foram utilizadas caixas de alumínio, que tiveram suas partes inferior e superior cortadas e higienizadas, servindo como base para a colagem das cartas. Outros materiais também podem ser considerados, porém, alguns oferecem um suporte menos rígido, como é o caso do papelão.

As cartas foram impressas em impressora comum estilo jato de tinta, recortadas e coladas com cola líquida branca que proporciona uma melhor fixação sem que ocorram falhas na tinta da impressão, posicionadas na face ilustrada da caixa de alumínio, deixando a parte lisa como o verso da carta (Figura 2). Deve-se manter atenção quanto a quantidade de cola, para que o papel não fique molhado e enrugado.

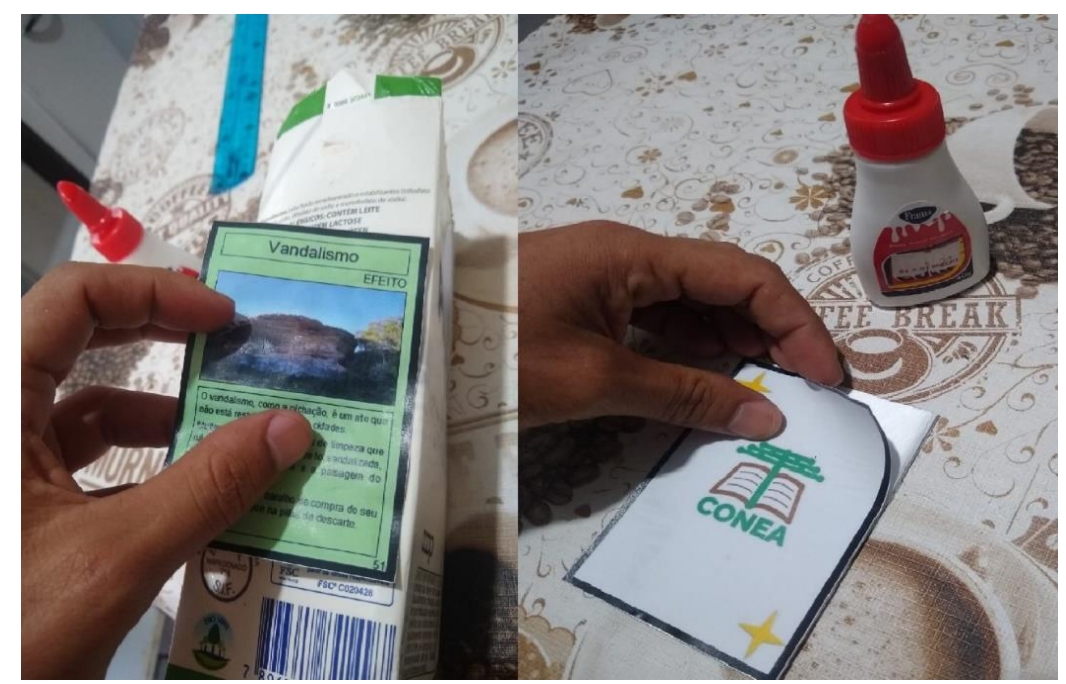

Figura 2: Imagens impressas e coladas na caixa de alumínio (frente e verso)

Fonte: autoria própria

Para aumentar a durabilidade das cartas foi utilizado papel tipo contact, que oferece mais resistência física, resistência a líquidos e protege o material quando realizada sua limpeza e higienização, pois funciona como uma película protetora. É um procedimento trabalhoso e que demanda prática para não formar bolhas nas cartas, porém o resultado é de perceptível qualidade. Outro método que pode ser empregado é a plastificação, contudo ela demanda 
maiores gastos financeiros. Porém, a carta plastificada tem maior flexibilidade e maior vida útil (Figura 3).

Caso seja de interesse destacar uma ou mais cartas, recomenda-se a não utilização de glitter em partes que contenham escrita e imagens, por acabar rasurando o conteúdo. Para o destaque, foi utilizado papel picado do tipo nacarado, entre a carta e a película, trazendo uma aparência brilhante e moderna para a carta (Figura 3).

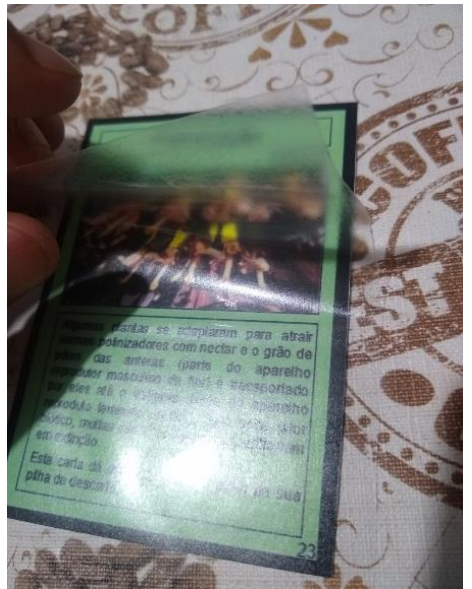

Figura 3: Proteção das cartas

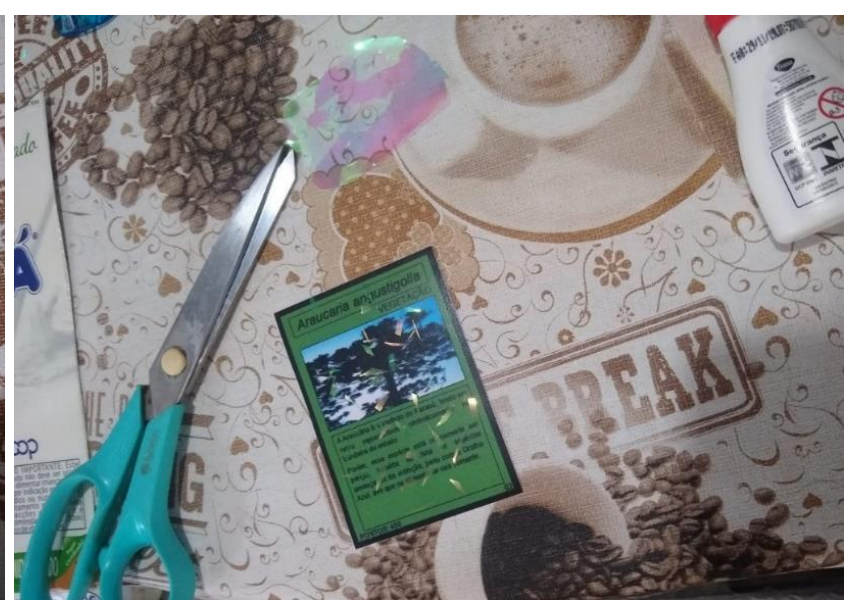

com papel tipo contact (esquerda) e nacarado (direita).

Fonte: autoria própria

O tabuleiro (Figura 4) possui medidas de uma folha A3 $(2 \mathrm{~mm}$ de largura por $297 \mathrm{~mm}$ de comprimento) sendo necessária sua impressão ou réplica manual.

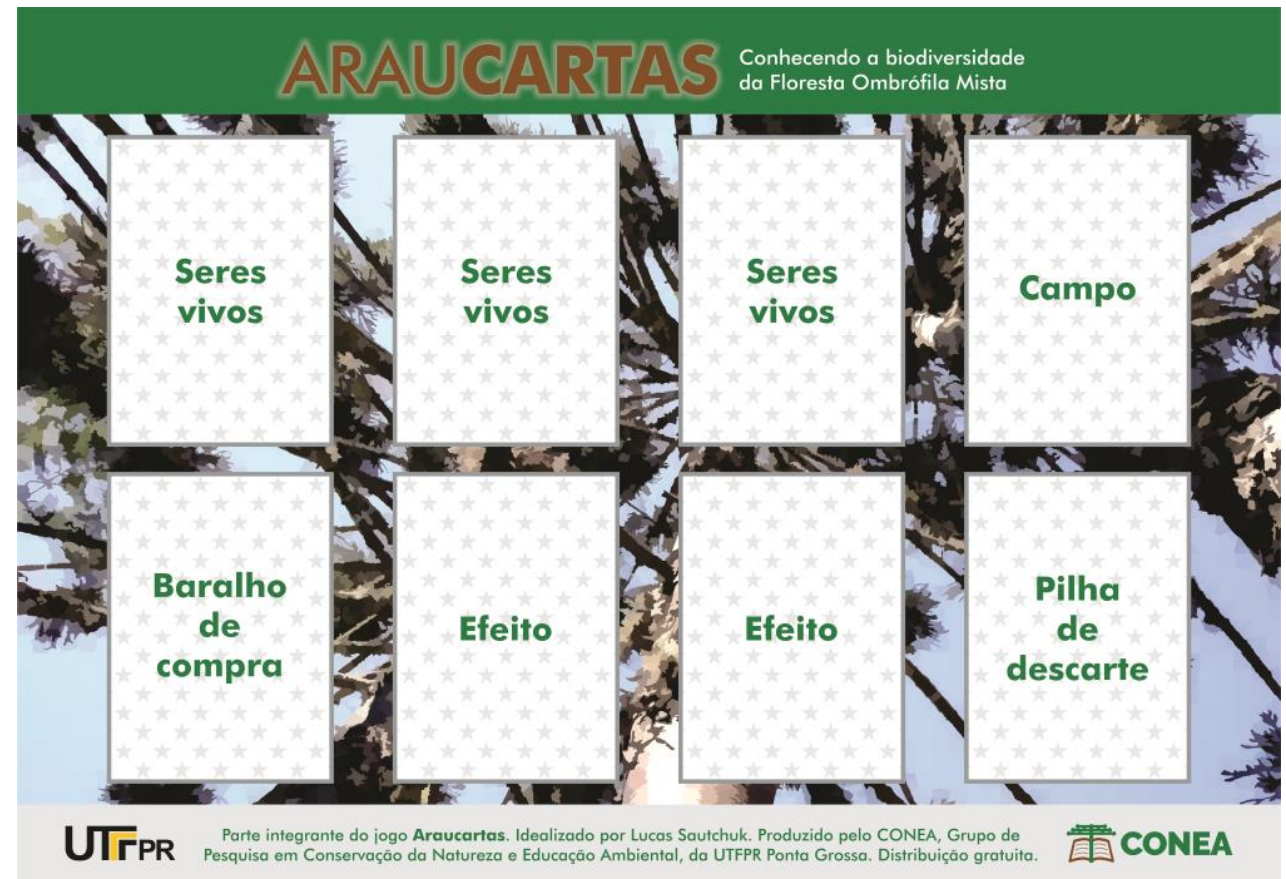

Figura 4: Modelo do tabuleiro

Fonte: autoria própria 
As 62 cartas que compõe o baralho possuem medidas de $6,8 \mathrm{~cm}$ de largura por 9,6 cm de comprimento. As cores escolhidas randomicamente para as cartas são ilustrativas para indicar a qual tipo pertencem, sendo que as cartas campo e efeito possuem um mesmo padrão de tons e as cartas do grupo dos seres vivos tem diferenças, como por exemplo as cartas tipo ave são azuis, enquanto as cartas tipo vegetação são de cor verde escuro.

As informações nas cartas (Figura 5) estão separadas em seis tópicos: o primeiro (canto superior) inclui o nome científico da espécie ou o nome da carta. Abaixo, indica-se a caracterização, seguida da imagem animal, planta ou tema da carta, seguido por uma breve descrição, sendo que esses quatro primeiros estão relacionados. No campo destinado à descrição pode também estar indicado um efeito que contém, finalizando com os pontos no canto inferior esquerdo (quando essa mecânica se aplicar à carta) e sua numeração sequencial (localizada no canto inferior direito), facilitando uma eventual substituição em caso de rasura.

Como o jogo traz a proposta inicial de apresentar a fauna e a flora da Floresta Ombrófila Mista, assim como problematizar sobre a conservação da natureza e trabalhar conceitos de Educação Ambiental, a regra inicial que difere da maioria dos jogos de cartas é que os pontos serão dados para o oponente e não retirados. Aquele que fizer o adversário receber um determinado número de pontos, ganha.

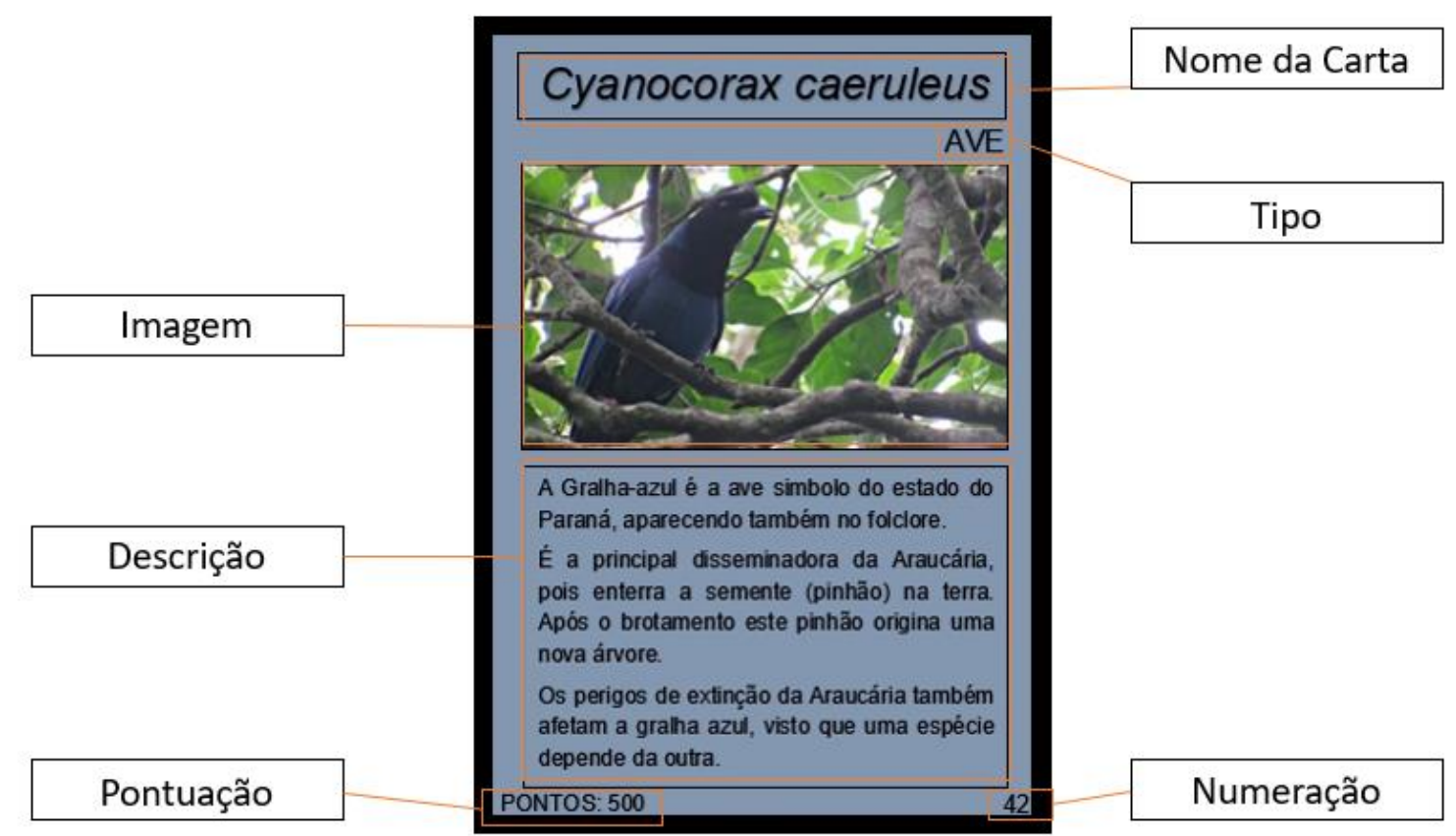

Figura 5: Informações nas cartas

Fonte: autoria própria

Para o jogo fluir e ter um tempo de duração suficiente para sua aplicação em aula, a quantidade máxima de pontos sugerida, que define que um jogador perdeu, é de 2.000 pontos ganhos. Essa quantidade de pontos 
pode ser aumentada ou diminuída, dependendo do objetivo do docente na utilização do jogo em sua aula.

Cada carta tem uma quantidade de pontos a ser acrescentada para o adversário, que irá variar entre 0 pontos a 500 pontos. Algumas cartas, chamadas de Carta Efeito, não possuem pontos, elas geram um efeito, como por exemplo, de retirar uma quantidade de pontos devido a ação simbólica que a carta representa, os efeitos variam de carta para carta.

O jogo inclui o tabuleiro e dois baralhos com 31 cartas cada, somando um total de 62 cartas. 31 cartas se referem a seres vivos e somam um total de 3.250 pontos, enquanto as outras 31 cartas totalizam 3.850 pontos. Além delas, cada baralho possui uma carta denominada "CAMPO" para as quais é aplicada uma mecânica de jogo própria.

As cartas em seu tamanho original e alta resolução, assim como o modelo do tabuleiro, estão incluídos no material suplementar do artigo.

\section{Regras do jogo}

Cada jogador fica com um baralho e embaralha suas cartas. Em seguida os jogadores devem colocar o baralho no tabuleiro no local onde está escrito "baralho de compra". Cada jogador compra cinco cartas do topo do baralho. Em seguida tiram "par ou ímpar" para decidir quem começa as jogadas, que serão alternadas entre os dois. Assim o jogo começa.

Primeiro turno: Cada jogador deve colocar cartas no local destinado no tabuleiro. O jogador não precisa (e não conseguirá) colocar todas as cinco cartas no tabuleiro, de uma só vez. Das cinco cartas que pegou do baralho antes do início do jogo, pode encontrar uma carta campo e algumas cartas seres vivos ou cartas efeito.

Cartas seres vivos: O jogador pode colocar no tabuleiro apenas uma carta dos seres vivos (vegetação, fungi, artrópode, animal terrestre ou aves), no local indicado. Só pode ser colocada uma carta deste tipo em cada turno.

Cartas Efeito: O jogador pode colocar até duas cartas efeito em cada turno, no local indicado. Este local deverá estar vazio para que a carta possa ser colocada. Assim que a carta efeito é colocada com sua frente virada para cima, seu efeito é aplicado no turno vigente. O jogador pode optar por colocar a (as) carta (s) viradas no tabuleiro. Assim, permite que o efeito da carta não seja aplicado e essas cartas efeito sejam viradas com a frente para cima em outro turno. Algumas cartas seres vivos possuem efeito. Verificar sempre após o nome da carta qual a sua categoria. Cartas que possuem a classificação de seres vivos seguidas da denominação "efeito" são chamadas de mistas e possuem pontuação baixa a ser dada para o oponente, mas em contrapartida, geram um efeito.

Carta Campo: Existe somente uma carta campo em cada baralho, a ser colocada no respectivo local do tabuleiro. A carta campo pode ser colocada no 
tabuleiro a partir do momento em que ela é comprada do baralho, permanecendo no tabuleiro até o final do jogo. Enquanto a carta campo estiver no tabuleiro, seu efeito é aplicado no início de cada turno.

Vez do oponente e somatório: Após as cartas terem sido colocadas no tabuleiro pelo jogador que ganhou no par ou ímpar, será a vez de seu oponente, que fará o mesmo procedimento. Em uma folha de papel, os jogadores irão escrever e somar quantos pontos eles ganharam de seu oponente. Após colocar as cartas no tabuleiro, são aplicados os efeitos descritos nas cartas (efeito e campo). Em seguida, o jogador deve informar o oponente quantos pontos a sua carta dos seres vivos está dando para ele (marcados no canto inferior esquerdo das cartas). Exemplo: se na carta estiver escrito "PONTOS: 400", o oponente receberá 400 pontos e deverá anotar no papel, para somar no fim do turno. Todos os pontos recebidos deverão ser somados.

Pilha de Descarte: Após somar todas as cartas seres vivos e efeito (se estiver com a frente virada para cima) de ambos os jogadores, elas são recolhidas e colocadas na "pilha de descarte". As cartas que estiverem na pilha de descarte não poderão ser mais utilizadas, exceto se um efeito de uma carta permitir que faça isso.

Segundo Turno: Nesta etapa cada jogador pode pegar apenas uma carta do topo do baralho (por turno). As regras do primeiro turno se aplicam aos próximos turnos até o final da partida. Importante: se o local do tabuleiro destinado à carta efeito estiver ocupado por uma carta com a parte de trás virada para cima, não poderá ser colocada outra no local. Somente no turno seguinte em que a carta efeito for virada, outra poderá ser colocada neste espaço do tabuleiro. Se o jogador ficar sem nenhuma carta na mão, o jogo prossegue.

No próximo turno ele irá comprar uma carta do topo do baralho. Nenhum jogador pode passar a sua vez. Não é obrigatório fazer uso de uma carta campo, uma carta dos seres vivos e duas cartas efeitos, em todos os turnos. O jogador precisa colocar no tabuleiro no mínimo uma carta por turno. Quem atingir 2.000 pontos antes perde o jogo, dando a vitória ao oponente.

Após o jogo terminar, o docente pode utilizar como método avaliativo a produção de um texto com o que o aluno aprendeu nas informações contidas nas cartas, ou desenvolver uma discussão sobre o tema de conservação da natureza.

\section{Acesso gratuito}

O material produzido foi disponibilizado no endereço https://sites.google.com/view/jogodecartasbiodiversidade/p\%C3\%A1gina-inicial. $\mathrm{O}$ acesso é gratuito estimulando seu uso em sala de aula, validando sua utilização como ferramenta de ensino-aprendizagem. No mesmo site está 
disponível um questionário para que o usuário possa avaliar Araucartas após o uso e contribuir com sugestões para melhoria do material.

O site possui cinco abas. A primeira é a página inicial, descrevendo a motivação da criação do jogo e uma breve biografia. A segunda aba disponibiliza as regras de forma simplificada com imagens exemplificando a mecânica do jogo.

A terceira aba do site inclui a "cartateca", espaço denominado para servir como a biblioteca das cartas criadas, onde é possível observar as informações das cartas com uma imagem em miniatura. A quarta aba é destinada ao download das cartas, das regras e do tabuleiro. A quinta aba é o local onde se encontra o formulário para avaliação.

\section{Possibilidades no ensino remoto}

Antiqueira e Sekine (2020) discutindo possibilidades de ressignificação para o enfrentamento do período atual e de pós pandemia, apresentam o cenário do ensino remoto onde professores foram alçados à condição de tutores on-line. A emergência de planejar e implementar aulas virtuais, estratégias didáticas para disponibilizar conteúdos em sites, sistemas e principalmente a necessidade de motivar alunos em fase escolar e vivendo em isolamento social a se dedicarem aos estudos.

As autoras questionam a ferida social que se tornou latente com a desigualdade na educação, haja vista alunos sem a mínima condição de participar das atividades escolares, seja pela falta das tecnologias e equipamentos, pela carência de ambientes tranquilos para o estudo ou mesmo fatores emocionais (ANTIQUEIRA; SEKINE, 2020). E nesse mesmo contexto nunca ficou tão clara a importância dos professores, com suas habilidades e motivações em meio à rotina atribulada do dia a dia, promovendo estratégias e criando materiais de fácil acesso para que os estudantes não ficassem esquecidos ou desmotivados, mas que ao contrário, vislumbrassem possibilidades mesmo no isolamento e nas restrições.

Araucartas foi implementado neste contexto, pois embora o planejamento inicial considerasse a construção do jogo com alunos e a aplicação presencial em sala de aula, fazendo uso de materiais reutilizados, um edital de fomento institucional permitiu a impressão de mil exemplares para distribuição em escolas públicas de Ponta Grossa. A impressão foi realizada em papel especial que permite sua higienização com álcool $70 \%$. Estas unidades foram estrategicamente distribuídas em escolas de periferia, nas quais alguns professores se deslocam até a residência dos alunos levando atividades para que possam acompanhar o ano letivo sem tantos prejuízos. 


\section{Conclusões}

O jogo que inicialmente foi planejado para uso presencial em sala de aula, foi modificado para realidade vivida na pandemia de COVID-19, com o ensino remoto. Esse momento vivido trouxe consigo a necessidade emergencial de adaptação de materiais para que professores tenham mais opções para trabalhar com os alunos, que podem aprender enquanto jogam em suas próprias residências.

Essa experiência mostra que além do professor se manter atualizado constantemente em relação à matéria que leciona, precisa se adaptar e se renovar para conseguir progredir, frente a novas adversidades e obstáculos.

Atualmente 0 jogo de cartas está sendo submetido à análise institucional para solicitação de patente, no entanto será assegurado seu acesso livre e gratuito.

Na próxima etapa dos estudos, será realizada uma análise sobre o uso que o recurso teve e se mostrou-se eficaz como estratégia complementar a ser utilizada no ensino remoto. Pretende-se avaliar também se Araucartas é uma efetiva contribuição para professores na árdua tarefa de ensinar e sensibilizar com constantes inovações, na busca de despertar o interesse dos alunos.

\section{Agradecimentos}

À CAPES pela concessão de bolsa de Iniciação à Docência (Edital PIBID 2018/2020) e de Residência Pedagógica (Edital RP 2020-2022) ao primeiro autor. À Diretoria de Extensão da UTFPR-PG por meio do edital 04/2020 - Apoio ao retorno de atividades presencias que subsidiou a impressão do jogo para distribuição em escolas públicas de Ponta Grossa. À Juliano Rodrigues Oliveira (Instituto Chico Mendes de Biodiversidade - Parque Nacional dos Campos Gerais) pela autorização do uso de imagens de sua autoria para finalidades educacionais sem obtenção de lucros. À Lucas Antiqueira pela autorização do uso de imagens de sua autoria e por todo serviço de formatação e diagramação das cartas e tabuleiro. À Elaine Teixeira da Silva e equipe da Floresta Nacional de Piraí do Sul, pelo apoio logístico na distribuição dos jogos.

\section{Referências}

ALVES, L.; BIANCHIN, M. A. O jogo como recurso de aprendizagem. Revista Psicopedagogia, São Paulo. v. 27, ed. 83, p. 282-287, ago. 2010.

ANTIQUEIRA, L.M.O.R.; SEKINE, E.S. Os erres Pós Pandemia: princípios para sustentabilidade e cidadania. Revista Brasileira de Educação Ambiental, v. 15, p. 70-79, 2020. 
ANTIQUEIRA, L.M.O.R.; MORO, R. S. Remanescentes de Cerrado no Parque Nacional dos Campos Gerais PR. In: CAMPOS, M. de A.; AZEVEDO, D.J.(Orgs). Biodiversidade Brasileira: Aspectos do Estado Atual 2. 2ed.Ponta Grossa: Atena, 2020, v. 1, p. 52-58.

BRAGA, N. C.; MACHADO, V. M.; FERREIRA, A. M. T. Jogo Didático "Protozooses do Brasil". Revista Brasileira de Educação Básica, v. 4, n. 12, p. 1-9, mar. 2019.

CAMBRÉA, V.C. Vamos Jogar? Jogos como recurso didático no ensino de ciência e biologia. Prêmio professor Rubens Murillo Marques, 2012. Disponível em: https://www.fcc.org.br/pesquisa/jsp/premiolncentivoEnsino/arquivo/textos/Texto sFCC 35 Vera Carolina Longo.pdf Acesso em: 15 mar 2021.

CANDIDO, C.; PRAMPERO, A.C.; SOARES, C.A.P.; GOMES, T.H.P. Recursos de Ensino e Aprendizagem: Elaboração de um material didático sobre o tema Artrópodes destinado a alunos do ensino fundamental e médio. Revista Cadernos de Pedagogia, São Carlos, v. 5, n. 10, p. 83-91, jan.-jun. 2012.

CAVALHEIRO, L. W.; NISHIJIMA, T. Uma situação de estudo como estratégia de educação ambiental à abordagem da problemática dos riachos degradados em uma escola. Pesquisa em Educação Ambiental, São Paulo, v. 9, n. 2, p. 10-22, 2014.

FERNANDES, S. M. A.; et al. Baralho Didático: Temas de Biologia para o Ensino Médio. Revista da SBEnBio, n. 7, p. 6974-6983. 2014.

FOCETOLA, P. B. M.; et al. Os jogos Educacionais de cartas como estratégia de ensino em Química. Revista Química Nova na Escola, v. 34, n. 4, p. 248255, nov. 2012.

KISHIMOTO, T. M. O jogo e a educação infantil. Edição Revista. São Paulo: Pioneira, 1994.

MELLO, M. S.; MORO, R. S.; GUIMARÃES, G. B. Patrimônio natural dos Campos Gerais. 2. ed. Ponta Grossa: Editora UEPG, 2010.

SILVEIRA, L.S. da; ALVES, J. V. O Uso da Fotografia na Educação Ambiental: Tecendo Considerações. Pesquisa em Educação Ambiental, vol. 3, n. 2 - pp. 125-146, 2008

TESSARO, J. P.; JORDÃO, A. P. M. Discutindo a importância dos jogos e atividades em sala de aula, 2007. Disponível em: https://www.psicologia.pt/artigos/textos/A0356.pdf . Acesso em 15 mar. 2021.

UHMANN, R.I.M.; VORPAGEL, F.S. Educação Ambiental em foco no ensino básico. Pesquisa em Educação Ambiental, vol.13, n.2 - pag. 53-68, 2018

VYGOTSKY, L. S. A formação social da mente. 4. ed. São Paulo: Livraria Martins Fontes Editora Ltda, 1991. 